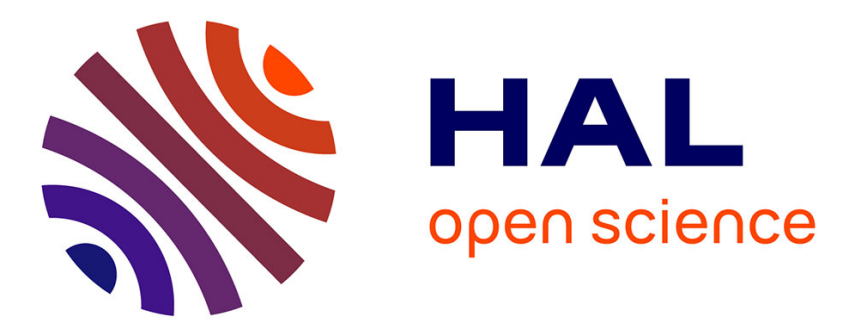

\title{
Deriving sonority from the structure, not the other way round: A Strict CV approach to consonant clusters \\ Joaquim Brandão De Carvalho
}

\section{To cite this version:}

Joaquim Brandão De Carvalho. Deriving sonority from the structure, not the other way round: A Strict CV approach to consonant clusters. The linguistic review, 2017, 34 (4), pp.589 - 614 . 10.1515/tlr-2017-0012 . hal-01647923

\section{HAL Id: hal-01647923 https://hal.science/hal-01647923}

Submitted on 11 Jan 2018

HAL is a multi-disciplinary open access archive for the deposit and dissemination of scientific research documents, whether they are published or not. The documents may come from teaching and research institutions in France or abroad, or from public or private research centers.
L'archive ouverte pluridisciplinaire HAL, est destinée au dépôt et à la diffusion de documents scientifiques de niveau recherche, publiés ou non, émanant des établissements d'enseignement et de recherche français ou étrangers, des laboratoires publics ou privés. 


\begin{abstract}
This paper aims to show that sonority-based generalizations on consonant phonotactics should directly follow from representations, not from stipulations on representations such as the commonly accepted licensing or government statements. The basic reason for this is that the second approach is both arbitrary and circular, as it entails a variable ranking of alleged well-formedness principles, if we want to explain, for example, why TR clusters may be either tautosyllabic or heterosyllabic depending on the language. I argue instead for a representational alternative assuming that (i) consonants and vowels are universally segregated, and (ii) involve two parallel CVCV sequences - one on the C-plane, the other on the V-plane - (iii) which may differ in length. It is shown how the major sonority categories, and thereby the phonotactic constraints based on these categories, naturally result from how the two $\mathrm{CVCV}$ sequences are synchronized if the one on the C-plane is longer than the one on the V-plane. It will also be seen how the proposed structures naturally account for several processes such as liquid metathesis and deletion, vowel epenthesis, plosive fricativization, etc., while providing a means for measuring the relative likelihood of some of them on the basis of representational markedness.
\end{abstract}

Keywords: phonotactics, consonant clusters, sonority, syllable structure, Strict CV. 


\title{
Deriving sonority from the structure, not the other way round: A Strict CV approach to consonant clusters*
}

\author{
JOAQUIM BRANDÃO DE CARVALHO \\ Université Paris 8 \\ CNRS UMR 7023 Structures Formelles du Langage
}

\section{Introduction}

Consonant clusters pose an interesting challenge for phonological analysis and theory. This concerns the way languages diverge as to the amount of phonotactic constraints they are subject to, the empirical generalizations that can be drawn from cross-linguistic diversity, and how these generalizations are handled by theoretical models. In what follows, I will first show how two basic types of clusters may be distinguished (Section 2.1), and how both types have been accounted for by representational approaches (Section 2.2). ${ }^{1}$ It will be seen that past work on the subject has moved along different lines which are all based on the notion of "licensing". It will be argued that these accounts suffer from at least one major drawback for a representational theory, as they need to turn supposedly well-formedness principles into hierarchically ordered constraints. I will then defend (Section 3) and develop (Section 4) a radically new approach to consonant phonotactics. This proposal is based on the assumption that planar segregation between consonants and vowels is a universal feature of phonological representations, and that the consonant and vowel planes may have different lengths. The major phonotactic constraints, commonly seen as involving features like [consonantal], [sonorant] or [continuant], depend on how these planes are synchronized, "sonority" being something which results from the structure, not the other way round. This theory will be shown to provide a straightforward account of a dozen well documented facts, from several generalizations on the combinatorial properties of onsets and coda+onset sequences, to such processes as liquid metathesis and deletion, vowel epenthesis or compensatory lengthening.

\section{Cluster typology and formal accounts}

\subsection{Bogus versus true clusters}

Empirical observation of consonant clusters across languages raises several questions, referring, e.g., to the maximal number of successive consonants allowed, to whether wordinternal clusters are tautosyllabic or not, whether there are vowelless words, etc. I shall focus on one particular issue: do clusters involve phonotactic constraints? The response to this question defines two major types of consonant sequences, which can be called "bogus" and "true" clusters. Languages may have either one of these two types or both.

Bogus clusters do not clearly show specific restrictions on manner and major class features, "specific" meaning "other than OCP-based constraints" (e.g., no more than one aspirated or ejective consonant in the word, etc.). In other words, the distributional restrictions on CCV sequences are the same as on CVCV. Typically, just as a language which admits /pati/ also allows /tapi/, so should any bogus CC-cluster (e.g., /pt/) have its mirror image (i.e. $/ \mathrm{tp} /)^{2}$

\footnotetext{
* I wish to thank Noam Faust, Shanti Ulfsbjorninn and three anonymous reviewers for their input on a previous version of this paper.

${ }^{1}$ Not surprisingly, much of the discussion will be centred on Government Phonology: until recently, issues concerning representations were largely outside the mainstream of research interests in constraint-based theories, markedness constraints being (at least implicitly) assumed to be phonetically grounded.

${ }^{2}$ At least potentially. Much of the literature on phonotactics is ambiguous on the question of whether unattested clusters are ill-formed, or mere accidental gaps. Most authors seem to opt for the first answer. For my part, while recognising its limitations, I follow Kuryłowicz's (1952) analogical principle, according to which, e.g., although
} 
Furthermore, just as the consonants in a CVCV sequence can have any laryngeal feature allowed in the language, so can bogus clusters be freely made up of any segments whatever their laryngeal features: cf. French mé[ds $]$ in 'doctor', $p a[\mathrm{~kb}]$ ot 'liner', Moroccan Arabic (MA) ktabna, katbu 'we/they wrote', etc. ${ }^{3}$

True clusters do exhibit, to a greater or lesser extent, restrictions as to manner and major class features. Thus, complex onsets are typically muta cum liquida sequences (/pl, $\mathrm{tr}, \mathrm{kr} . . . /)$. Though allowing a "formidable array of possibilities" (Cyran and Gussmann 1999: 219), Polish obeys relatively strict constraints: as shown by words like [pstrõnk] pstrąg 'trout', [p $\left.\int \varepsilon s t \tilde{\varepsilon} m p s t f o\right] ~ p r z e s t e ̨ p s t w o$ 'crime', clusters consisting of more than two consonants involve alternation of plosives, fricatives and sonorants. The same goes for Georgian, whose long sequences of consonants, such as the famous one in prtskvnis 'he is peeling', "are far from arbitrary", being "composed entirely of sub-clusters that are consistent with [Selkirk's (1984) and Clements's (1990)] Sonority Sequencing Principle” (Butskhrikidze 2002: 156).

On the other hand, unlike bogus clusters, true clusters strictly share the same laryngeal feature: cf. Polish obstruent clusters (Kuryłowicz 1952; Cyran and Gussmann 1999), ${ }^{4}$ the socalled Georgian harmonic clusters (Chitoran 1998), etc. Note that this represents a limited departure from the usual definition of bogus and true clusters; as a working hypothesis, an obstruent cluster that does not agree in voicing will be viewed as necessarily bogus, whereas one that does may or may not be bogus, according to whether or not it is unconstrained.

The difference between bogus and true clusters is paralleled by a similar one between unconstrained and restricted codas in both word-internal and word-final positions: for example, while any of the Arabic consonants may occur in coda, Ibero-Romance codas are typically sonorants (plus the fricative /s/).

Interestingly as will be seen, bogus clusters often add a syllable to the word, either by means of epenthesis (Fr. mé[dəs]in-mé[ds]in 'doctor', $p a[\mathrm{k} ə \mathrm{~b}] o-p a[\mathrm{~kb}] o t$ 'liner', $p([ə])$ lousep'louse 'lawn', j' d[ə]mande-j[ə] d'mande 'I ask', MA ktəbna, kətbu 'we/they wrote'), or through consonant syllabicity (Czech $v l k$ 'wolf', Serbo-Croatian (SC) krvi 'blood (gen.)').

True clusters, however, do not generally involve nucleus creation, whatever the number of their members. Unlike pelouse, Fr. blouse has no schwa; while *j' d'mande is impossible, and implies at least one schwa, $(j$ ') crois 'I believe', with a 3-member cluster, is allowed, and $c r$ cannot be broken up. ${ }^{5}$ Contrary to SC krvi, Polish krwi is monosyllabic (Scheer 2009). There are only two typical cases in which true clusters may generate syllabicity: final complex onsets (whence vowel/zero alternations such as Latin magister/magistri), and initial $s+$ consonant sequences (as in European Portuguese [J]pelho-[i]]pelho 'mirror').

\subsection{May principles be ranked?}

Nucleus activation and absence of phonotactic constraints constitute primary evidence for the thesis that clusters may contain empty nuclei, a view that has been supported by Government Phonology (henceforth GP), and generalized within the Strict CV framework (Lowenstamm

\footnotetext{
the cluster / $\mathrm{xn} /$ is unattested in Polish, it must be viewed as legal, since it is the fourth proportional in /gm/ : /gn/ :: /xm/ : /xn/, where the three other clusters are all attested. Thus, for example, French can be said to allow both /pt/ and /tp/, though the latter is unattested, as /pt/ (petit 'small'), /bd/ (bedeau 'beadle') and /db/ (debout 'standing') can all be found.

${ }^{3}$ Note that voice(less)ness assimilation, if any, is variable and gradual in French (cf. Léon 1996: 71), and does not generally entail neutralization, so that, e.g., ach(e)ter 'buy' and à j(e)ter 'disposable' remain distinct.

${ }^{4}$ Even $k r w(i)$ 'blood (gen.)', where $w$ comes from */w/, may be voiceless ([krf]i), unlike Serbo-Croatian [krv] $i$.

${ }^{5}$ More specifically, a syllabic peak, if any, will not be perceived as such by the speakers. Polish (true) clusters, as in ptak 'bird', and even muta cum liquida sequences, as in Portuguese crer 'believe', do involve a burst and a schwa-like vowel between the consonants; yet, ptak is perceived and treated as a monosyllable, as opposed to French petit 'little', and so is crer, by contrast with querer 'want' (cf. Section 3.2).
} 
1996; Scheer 2004). Strictly speaking, however, the empty nucleus assumption seems quite intuitive in the case of bogus clusters only: if a $\mathrm{C}_{1} \mathrm{C}_{2}$ cluster allows a schwa between the consonants, ${ }^{6}$ and if both consonants may be any of the segments attested in the language, then the consonants of $\mathrm{C}_{1} \mathrm{C}_{2}$ behave exactly as those of $\mathrm{C}_{1} \mathrm{VC}_{2}$, that is as if both were onsets, and if there were a nucleus between them - and this is why such clusters are bogus.

Accordingly, as illustrated in (1), a representation in which there is an empty nucleus between the consonants, and where this empty nucleus is properly governed by a full nucleus (here at its right) seems to be well designed to provide a natural account of bogus clusters, since Proper government (henceforth PG) is assumed to license the empty nucleus, while being "insensitive to the nature of the neighbouring onsets" (Cyran and Gussmann 1999).

a. MA [ktəbna] 'we wrote'

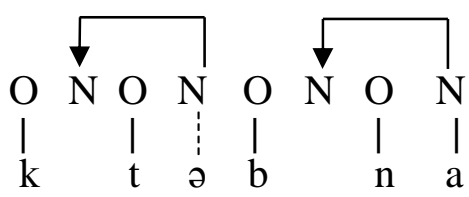

b. MA [kətbu] 'they wrote'

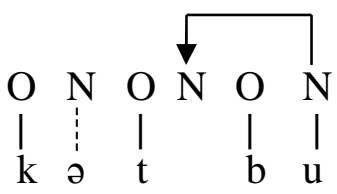

But how should true clusters be explained? As regards syllabicity, past work has moved along two different lines, which may coexist in GP. The first, built on the well-known representation of syllable structure which dates back to Pike and Pike (1947) and Kuryłowicz (1948), has long been the mainstream view in phonology. It is based on the assumption that such clusters involve branching constituents like complex onsets and rhymes, whence tautosyllabic clusters and coda+onset sequences. As there is no empty nucleus, neither vowel epenthesis nor syllabic consonants are expected.

According to the second line of research, clusters - including our true clusters, in the case of the Strict CV model - involve empty nuclei. Since PG does not predict any phonotactic constraint, other mechanisms had to be proposed to both license the empty nuclei, and generate the required restrictions on segment combination. ${ }^{7}$

These restrictions have generally been formulated in terms of licensing possibilities associated to prosodic constituents (cf. Goldsmith 1990: 123-127). In many cases, however, these approaches suffer from formal arbitrariness in the sense of Chomsky and Halle (1968: Ch. 9). For example, why should the branching structure of muta cum liquida (henceforth TR) sequences be associated with rising sonority? Licensing statements too often appear as stipulations on representations; they do not follow from representations. Hence, the notion of "ability to license" assigned to a given node or slot bears an unfortunate resemblance to Molière's "dormitive principle", that is "a type of tautology, in which an item is being explained in terms of the item itself, only put in different [...] words" (https://en.wiktionary.org/wiki/dormitive_principle).

Within GP, however, there have been interesting attempts to motivate phonotactic restrictions. Besides PG between nuclei, which results in a coda+onset sequence as in (1a,b), two other "lateral" relationships involving headedness have been proposed: Gussmann and Kaye's (1993) Interonset Government (IO), and Scheer's (2004) Infrasegmental Government (IS). Both are based on the idea that, in a complex onset, one of the consonants governs the

\footnotetext{
${ }^{6}$ Either optionally, as in the French examples above (médecin, paquebot), or as a strategy to avoid heavy CCC clusters (French je demande, Moroccan Arabic ktabna, katbu).

${ }^{7}$ In what follows, I will leave aside Magic Licensing (Kaye 1992), which handles the falling sonority sequences, typical of word-initial sC clusters, and the Domain-final parameter, which involves extra-phonological aspects; only possible tautomorphemic clusters will be considered here.
} 
other, licensing thus the enclosed empty nucleus. The major difference is that in IO the obstruent governs the sonorant, while the reverse relation is supposed by IS. ${ }^{8}$ The interesting point is that in both cases the prosodic strength of a slot is in relation to the amount of phonological material it bears, following on from Harris's (1997) idea of Licensing Inheritance, whereby prosodically weak positions may not be able to license excessively complex segments. Hence, while obstruents, which are governors, are supposed to be more complex than sonorants in IO, the reverse is assumed in IS, where obstruents are governees.

Interestingly, the sole real attempts to motivate phonotactic restrictions have come to deny the primacy of "sonority" - a notion which dates back to Jespersen (1913), and has long been viewed as constitutive of syllable structure. According to the IO/IS assumption, sonority is reducible to segmental complexity (cf. Harris 1990, Rice 1992, Cyran 2008, 2010). I will not discuss this thesis, whose variants crucially depend on one's views on independent issues like feature specification and segmental markedness. The important point is that, whether or not based on sonority, both IO and IS come up against a major problem.

Consider again the case of TR sequences. The tautosyllabicity of such clusters is handled by IS as in (2a), where the sonorant attached to $\mathrm{O}_{3}$ governs the obstruent in $\mathrm{O}_{2}$. As a result, the whole $\mathrm{O}_{2} \mathrm{~N}_{2} \mathrm{O}_{3}$ sequence constitutes a government domain, where the empty $\mathrm{N}_{2}$ is licensed without having to be properly governed by $\mathrm{N}_{3}$. However, this is not always the case: many languages, like Arabic, Hebrew, Berber or Turkish, lack complex onsets; yet, they also show word-internal TR clusters, which are treated as heterosyllabic like all other-CC- sequences. Hence, the same cluster is obtained either by IS, as in (2a), or by PG, as in (2b), where, $\mathrm{N}_{2}$ being properly governed by $\mathrm{N}_{3}$, TR constitutes a bogus cluster.

a. Italian /sakra/ 'sacred (fem.)'

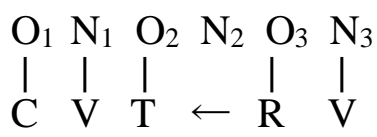

\section{b. Hebrew /sakra/ 'she scrutinized'}

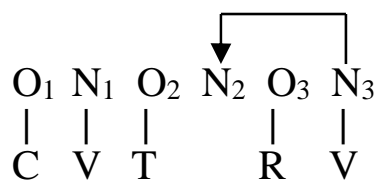

In sum, IS and PG compete for licensing the empty $\mathrm{N}_{2}$ of TR sequences: either the Sonority Sequencing Principle (or some complexity-based constraint) underlying IS wins (along with NoCODA), and PG is either impossible or at least unnecessary, as in Italian, or PG applies, entailing IS (and NoCODA) violation, as in Hebrew. ${ }^{9}$

It may seem strange that well-formedness principles of a representational theory like GP behave as constraints à la OT. Should we then admit that the necessity to rank IS and PG (plus Magic Licensing?) simply shows that phonology is nothing else than a constraint-based system, and that harmonic grammars provide the most accurate account of cluster typology? I do not think so, and I will propose an alternative solution to the problem raised by current representational accounts: arbitrary differences such as the one between Italian and Hebrew in (2) are not explained through equally arbitrary ranking. Note that it is not the concept of constraint hierarchy in general that is at issue here: OT has clearly demonstrated that ranking variability between markedness and faithfulness is at the heart of phonological computation which is, moreover, the basic failure of a representational theory like GP. What I challenge is

\footnotetext{
${ }^{8}$ Note that IO accounts for only part of complex onsets, since (binary) branching structure is preserved in GP. This is due in particular to specificities of Slavic morphophonology that will be left aside here.

${ }^{9}$ Note that languages allowing highly complex clusters like Polish pose the very same problem, and two additional ones: (i) the indeterminacy as to which mechanism applies in certain forms (particularly when no morphological alternation supports the existence of an empty nucleus), and (ii) the application of PG across an IO domain, as in tknać 'touch', which violates the Strict Locality Principle (cf. Cyran and Gussmann 1999).
} 
the idea that there should be a hierarchy between markedness statements such as IS and PG, whose ranking cannot be justified through interaction with independent faithfulness constraints. We should prefer a theory in which (un)markedness is built-in into representations: Italian /sakra/ and Hebrew /sakra/ do not differ from each other because they are subject to two differently ranked constraints, or to two different government stipulations, but simply because the two forms have different structural representations. ${ }^{10}$

\section{A representational alternative to constraint interaction}

\subsection{The paradoxical nature of complex onsets}

Let us assume that only bogus clusters, as in $(1,2 b)$, necessarily involve an empty nucleus (cf. Section 2.2). What, then, are true clusters, like the TR sequence under (2a)? An adequate representation of such sequences should satisfy the three criteria in (3) that follow from previous discussion.

(3) a. Phonotactics:

Does the TR sequence unambiguously follow from the representation?

b. Cohesiveness:

Does the representation explain cluster cohesiveness (cf. j' crois, not *j' c[ə]rois)?

c. Syllabicity:

Does the representation explain the particular cases of epenthesis (cf. magister)?

Let us assess four basic autosegmental configurations against these criteria. The structure in (4a) is reminiscent of, say, Clements and Keyser's (1983) CV phonology. The one under (4b) may be interpreted as a single onset associated with two skeletal slots, as in most GP work (cf. Charette 1991). The representation in (4c) has been proposed by Szigetvári (1999), Scheer and Szigetvári (2005) and Blaho (2008). The structure in (4d) is the one supported by the Strict CV framework (Scheer 2004), and partly by GP (Gussmann and Kaye 1993). The table in (4) shows the answers given by each representation to the questions under (3).

(4)

a.

\begin{tabular}{c|ccc} 
& Phonotactics & Cohesiveness & Syllabicity \\
\hline C C V & & & \\
$\mid$ T | & NO & YES & NO \\
T R & & &
\end{tabular}

b.

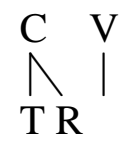

NO

c.

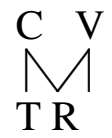

d.

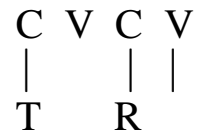
10 Thus, the same sequences may be true in some languages or dialects, and bogus in others. For example, forms
like fil[ə]m, far[ə]m, found in many Irish and Scottish dialects, have bogus clusters, as evidenced by epenthesis. 
Faced with the question in (3a), the structures in $(4 a, b)$ suffer from a fundamental flaw: nothing but ad hoc stipulations distinguishes /pr, tr, kr/ from, say, the Greek clusters /ps, ts, $\mathrm{ks} /$. The representations in $(4 \mathrm{a}, \mathrm{b})$ also behave alike vis-à-vis $(3 \mathrm{~b}, \mathrm{c})$ : since they contain no empty nucleus, they explain why TR sequences, unlike bogus clusters, generally do not allow epenthesis, but fail to account for the particular cases where they do, as in Latin ager, magister, etc.

The representations in $(4 \mathrm{c}, \mathrm{d})$ are interesting in that they provide complementary answers to the questions in (3). If it is assumed that sonorants, and only sonorants, are segments which are ambiassociated to both $\mathrm{C}$ and $\mathrm{V}$, then (4c) is the only configuration that provides a natural account of the sonority slope. Lacking an empty nucleus like (4a,b), (4c) also explains why TR sequences cannot be generally broken up, but, for the very same reason, it is not clear why epenthesis may occur under certain circumstances. As to (4d), it fails to give a positive answer to the questions in $(3 a, b)$, since nothing in the representation itself - i.e. apart from additional stipulations like ranking IO/IS over PG - differentiates TR sequences from bogus clusters (cf. Section 2.2). Furthermore, if TR sequences are to be represented as CVCV, PG may apply across a government domain, as in Polish tkliwy 'tender', French j' crois, un s'cret 'a secret', and thus violate Strict Locality (Kaye et al. 1990). However, (4d) is the only structure that succeeds in allowing epenthesis, since it has an empty nucleus.

We are then left with an apparent paradox: the adequate representation of TR clusters should be the one which is both (4c) and (4d)! In other words, this representation should be able to show that:
a. TRV sequences have two skeletal bases: CV and CVCV;
b. $\mathrm{R}$ is somehow associated with both $\mathrm{C}$ and $\mathrm{V}$.

\subsection{Clusters as an effect of $C / V$ alignment}

Paradoxes like the one in (5a) are not unprecedented in phonology. Consider the case of long vowels within classic unilinear theories. Let us take the example of a language L where stress generally falls on the first syllable, as in [képi]. However, if the rhyme of this syllable has a long vowel or a sonorant coda, stress causes either a falling or a rising pitch according to the word, whence [kê:pi] $v s$ [kě:pi] and [ké:m̀pi] $v s$ [kè:mipi]. Also, L has a language game which consists in syllable inversion: [képi] gives [píke]. However, if the word contains a long vowel, length does not move: [kê:pi] gives [pî:ke], not *[pîke:]. The paradox resides in that the long vowel [e:] behaves as if it was phonemically both /ee/ (with respect to stress) and /e/ (in the word game), that is sometimes as a cluster, sometimes as a single segment.

We now know that there is no paradox. But this was made possible by a radical change in phonological representations, in which the unilinear sequence of letter-like segments gave place to a more complex structure made of positions and melodies, long vowels resulting from association of a single set of melodies with two positions, as shown in (6).

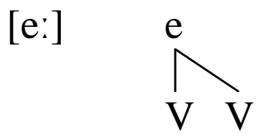

It follows that there may be two sorts of processes: those which are position-sensitive, like stress rules, and those which are segment-sensitive, like the language game above. In other words, "from the point of view" of stress, as it were, [e:] appears as twofold, since stress falls on positions, not on segments, while metathesis "sees" it as a singleton, since it manipulates 
segments, not positions. My claim is that TR clusters give rise to the same kind of ambiguity as [e:]: both CV and CVCV representations for TRV are right, but only partially right.

Like length, complex onsets will then be assumed to result from synchronization: TRV sequences emerge if, and only if, the CVCV and CV patterns match as in (7a), where $\mathrm{C}$ and V are replaced with $\mathrm{O}$ (nset) and $\mathrm{N}$ (ucleus). The duplication of $\mathrm{ON}$ sequences is based on the idea that consonants and vowels occupy different planes, and that $\mathrm{C} / \mathrm{V}$ segregation is much more than a particular aspect of Semitic morphology. For lack of space, I will not dwell on the many arguments - from acoustic (Öhman 1966) to acquisitional (Macken 1992; McDonough and Myers 1991) and cognitive (Obleser et al. 2010) evidence - which support that "consonants and vowels belong to separate channels in the speech 'plan', but must interact through implementation in the same vocal tract" (Fujimura 1992). I propose that CVCV and $\mathrm{CV}$, as OnOn and oN respectively, occupy the consonant and the vowel planes, which may thus differ in length, as shown in (7a) in contrast to the structure of bogus clusters under (7b).

a.

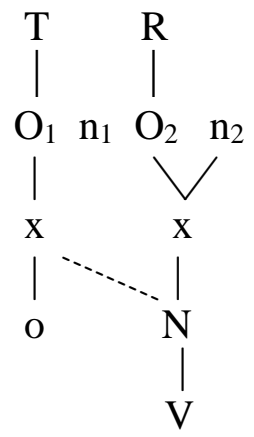

b.

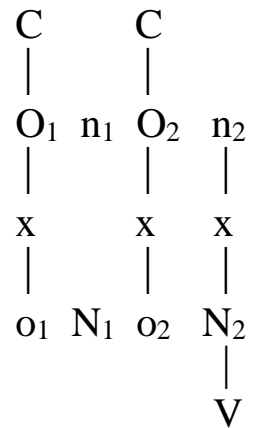

C-plane

skeleton

V-plane

For the sake of brevity, the onsets in the C-plane and the nuclei in the V-plane will be referred to by means of capital letters $(\mathrm{O}, \mathrm{N})$, while the onsets in the V-plane and the nuclei in the Cplane will be written with lowercase letters $(o, n)$.

The structure in (7a) requires further explanation on four points. Firstly, it contains an " $\mathrm{x}$ slot" skeleton, which serves as the temporal interface between the C- and the V-planes. An argument for its relevance will be seen in Section 4.2. In (7a), TRV has been assigned only two slots, that is the number of elements in the V-plane (oN). At this stage, this can be simply attributed to Occam's razor, but, as will be shown in Section 4.3, the difference between 2and 3-slot configurations may lead to different predictions.

Secondly, as is shown in (7a), $\mathrm{O}$ and $\mathrm{N}$ behave both as positions, since they bear segmental content (T, R, V), and as melodies, since they are linked with skeletal slots. Hence, as in Encrevé's (1988) account of French liaison, not only are there such things as empty onsets and nuclei, but these empty categories may either be linked with the skeleton (giving / $/$ and $/ \partial /$ ), or float (lacking phonetic interpretation), like the C-plane $\mathrm{n}_{1}$ in (7a).

Thirdly, being melodies, onsets and nuclei are subject to the Obligatory Contour Principle: there should not be adjacent onsets and nuclei, whence the C-plane $\mathrm{n}_{1}$ in (7a). Note, however, that this $\mathrm{n}_{1}$ of TR clusters is typically realized as a burst in at least some languages like Portuguese (Martins 1986: 138). Furthermore, as will be seen in Section 4, far from being a simple effect of OCP, the C-plane $\mathrm{n}_{1}$ in (7a) also plays a crucial role in phonotactic theory.

Lastly, $\mathrm{N}$ propagation to the preceding onset, shown by the dotted line in (7a), involves consonant voicing: cf. Carvalho (2008) for the rationale behind this proposal. The importance of this point will be made clear in Section 4.2.

What do we gain by assuming the configuration in (7a)? Several points can be noted at this stage, among which positive responses to all the questions in (3). First, it follows from (7a) 
that sonority categories are emergent properties of $\mathrm{C} / \mathrm{V}$ synchronization. Obstruents $(\mathrm{T})$ and vowels (V) result respectively from $\mathrm{O}$ and $\mathrm{N}$ positions linked to a slot of their own. In addition to these basic categories, sonorants will be defined as in (8). ${ }^{11}$

(8) Sonorants (R) are melodies associated with O positions which:

a. share a slot with an adjacent $\mathrm{n}$ of the C-plane,

b. and are aligned with a $\mathrm{N}$ of the $\mathrm{V}$-plane.

These characteristics capture the idea expressed in (5b) that $\mathrm{R}$ is somehow linked to both $\mathrm{C}$ and V. Constraints based on the relative complexity of obstruents and sonorants (cf. Section 2.2) become unnecessary, as sonority is built-in into representations.

Secondly, TRV counts as one syllable, which cannot be broken up, unlike bogus clusters. Let us assume that:

(9) The number of (perceived) syllables equals the number of $\mathrm{n}-\mathrm{N}$ alignments.

The empty C-plane $\mathrm{n}_{1}$ of TR clusters, albeit often realized as a burst of $\mathrm{T}$, cannot be perceived as a syllable peak (cf. note 5), as it does not have a "vocalic expression" in the V-plane. It does, however, in word-final TR clusters, which may develop either o-epenthesis or Rsyllabicity by $\mathrm{n}_{1}$-association and resulting $\mathrm{n}_{1}-\mathrm{N}$ alignment, as shown in (10). (How the empty n's of the C-plane are licensed will be discussed in Section 4.1).

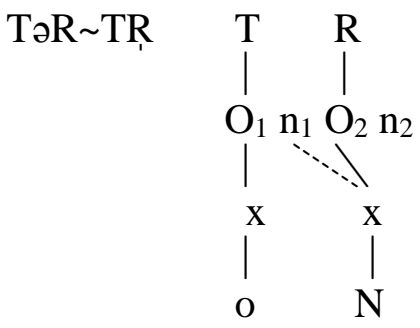

The result of epenthesis is often lexicalized at a later stage of historical evolution, whence allomorphies like Latin ager 'field' / agri (gen.), Serbo-Croatian dobar 'good' / dobra (fem.).

Fourthly, since PG is a relation between successive V-plane N's, it can naturally apply over a C-plane n, e.g. across a true cluster in TəTRV sequences, as in French (j'ai un) s'cret 'I have a secret', without having to violate the Strict Locality principle (cf. note 9), as shown in (11). Being properly governed by the $\mathrm{V}$-plane $\mathrm{N}_{2}, \mathrm{~N}_{1}$ is delinked, which causes [ə]-deletion owing to the assumption under (9).

\footnotetext{
${ }^{11}$ In fact, the term "sonorants" should be replaced here with "liquids". Nasality seems to be a floating feature that acts as a "double agent", nasal consonants behaving sometimes as obstruents - they can be labial; Slavic languages allow /ml/ onsets (cf. Zec 2007 for Bulgarian); Ancient Greek has /mn/ along with /pt, ps/; NC homorganic sequences cannot be broken up, like (plosive) geminates, etc. -, sometimes as sonorants - general absence of voice contrasts; Ancient Attic Greek /pn, kn/ behave like muta cum liquida clusters, not as /pt, kt, ps, ks/; /l/ becomes [n] when nasalized in Galician-Portuguese; apart from /s/ (and the first member of geminates), nasals and liquids are the sole consonants allowed in coda position in many languages, etc. Accordingly, nasality may be linked to a $\mathrm{C}$-plane $\mathrm{O}$ that can be aligned either with a V-plane o (hence a plosive) or with a V-plane $\mathrm{N}$ (hence a sonorant). Moreover, in many languages nasality may be located on the V-plane as well (hence phonemic nasal vowels and glides). As for glides, it will be assumed that they occupy the V-plane (cf. Section 5). I will leave these issues for further analysis.
} 


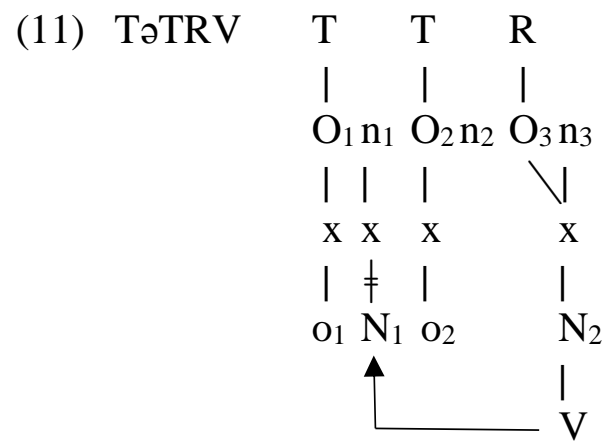

Lastly, and more importantly, the problem raised by principle ranking (Section 2.2) disappears, as the structure in (7a) is different from that of a bogus cluster in (7b), which contains an additional oN sequence in the V-plane, i.e. C- and V-planes of equal length.

\section{Extending the theory}

\subsection{Obstruent+sonorant clusters}

Assuming the double $\mathrm{ON}$ sequence in the $\mathrm{C}$ - and $\mathrm{V}$-planes, the question arises of what such seemingly strange objects as "consonantal nuclei" are. Let us consider two questions:

(12) a. If empty, how are C-plane n's licensed to be silent?

b. If not, what may n's bear?

As regards (12a), the comparison between the structures in (7a) and (10) suggests that the relations at work in the C-plane can be handled by (a slightly revised version of) the Empty Category Principle (ECP) defined by GP: (i) an empty C-plane $\mathrm{n}$ floats if it is governed by a $\mathrm{n}$ at its right (or if it is word-final); (ii) only a $\mathrm{C}$-plane $\mathrm{n}$ aligned with a $\mathrm{V}$-plane $\mathrm{N}$ can govern another $\mathrm{n}$ at its left. As a result, there cannot be two successive unlicensed empty C-plane n's: either $\mathrm{n}_{1}$ is governed by $\mathrm{n}_{2}$, as in the complex onset under (13a), or $\mathrm{n}_{1}$ is anchored and $\mathrm{n}_{2}$ is licensed because it is word-final, as in (13b), or governed by a following $n$, if any. In the latter case, there is no cluster, but a vowel and a sonorant coda. (Melodic association is indicated, but segmental content is omitted; $t$ and $d$ in the gloss stand for voiceless and voiced obstruents; the voiced onset results from $\mathrm{N}$ left propagation shown by the dotted line.)
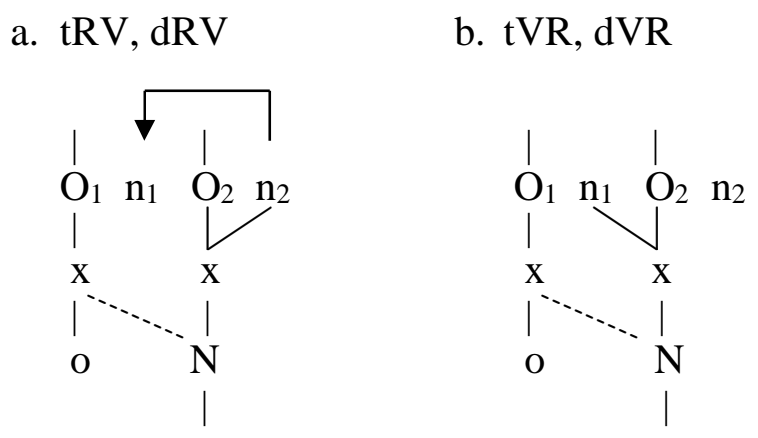

c. $\mathrm{tVt}, \mathrm{dVt}$

The representations in $(13 \mathrm{a}, \mathrm{b})$ provide a straightforward explanation of three interesting issues about sonorants. The first is the well-known tendency across languages towards codas primarily licensing sonorants (cf. Hyman 1985). As shown in (13b), sonorant codas, i.e. $\mathrm{O}_{2}-\mathrm{N}$ 
alignments, naturally follow from OnOn/oN synchronization and $\mathrm{n}_{1}-\mathrm{N}$ alignment. ${ }^{12}$ In contrast, a plosive coda would suppose O-o alignment after the vowel, whence an additional oN in the V-plane, as in (13c); thus, plosive codas are not "true" codas, as they imply an empty V-plane $\mathrm{N}$ at their right, just like the first member of the bogus cluster in (7b).

The second issue is the metathesis of the type TVR $\leftrightarrow$ TRV, of which South-Western Sardinian offers a well-documented example (Lai 2013). Consider Lat. porta, porcu > prota 'door', procu 'pig', where a liquid coda becomes the second element of a complex onset. ${ }^{13}$ Interestingly, \#VR is preserved and does not give \#RV (arcu, herba > id.). In fact, $\mathrm{R}$ does not move; only the $\mathrm{n}-\mathrm{N}$ alignment does, from its place in (13b) to the one in (13a), which supposes the asymmetry between the $\mathrm{C}$ - and the V-planes found in both TVR and TRV sequences, but crucially not in RV.

Thirdly, given a preconsonantal TR cluster, as in French quatre gars 'four boys', my proposal accounts for two attested possibilities: (i) either the V-plane $\mathrm{N}_{2}$ does not properly govern $\mathrm{N}_{1}$, and the C-plane $\mathrm{n}_{2}$ can align with the $\mathrm{V}$-plane $\mathrm{N}_{1}$, and thus govern the C-plane $\mathrm{n}_{1}$, yielding a schwa, as in (14a) qua [ţəga]; (ii) or the $\mathrm{V}$-plane $\mathrm{N}_{2}$ does govern $\mathrm{N}_{1}$, involving $\mathrm{N}_{1}$ delinking, which prevents both $\mathrm{O}_{2}-\mathrm{N}_{1}$ and $\mathrm{n}_{2}-\mathrm{N}_{1}$ alignments, and therefore entails the deletion of the entire $\mathrm{O}_{2} \mathrm{n}_{2}$ sequence in order to satisfy the ECP, as in (14b) qua[tga].
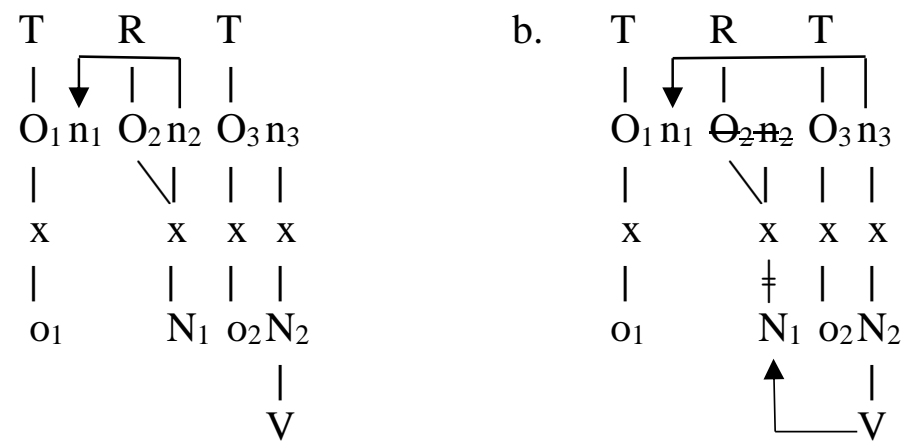

\subsection{Obstruent+obstruent clusters}

Let us now address the question in (12b): what kind of segments may the nuclei of the Cplane bear? Those segments are expected to evidence a remarkable property: they should not develop epenthesis, since they themselves occupy the nucleic position. Now, as opposed to sonorants, which may favour epenthesis since they involve empty C-plane n's, fricatives evidence the expected behaviour. Assuming that the C-plane n, along with n-o alignment, is the structural position allowed to fricatives, compare Latin ager 'field', instead of *agr, in (15a), with pax 'peace', instead of *paces, in (15b), or Fr. br[ə]bis 'sheep' with $e$ [kst]ase 'ecstasy', not*e[ksot]ase.

a. $/-\operatorname{Tr} \# />[-\mathrm{TVr} \#]$

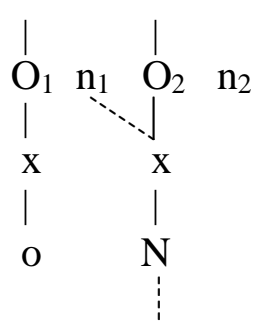

b. /-Ts\#/ > [-Ts\#]

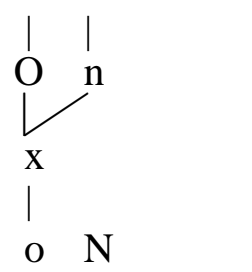

\footnotetext{
${ }^{12}$ Hence, no additional statements on the licensing power of codas or of the following empty nuclei are needed.

${ }^{13}$ Cf. also Latin formaticum, berbicem, turbulare > French fromage 'cheese', brebis 'sheep', troubler 'trouble'.
} 
Let us then consider the structures in (16), which follow from OnOn/oN synchronization. ( $t$ and $d$ stand for voiceless and voiced plosives, $s$ and $z$ for voiceless and voiced fricatives.)
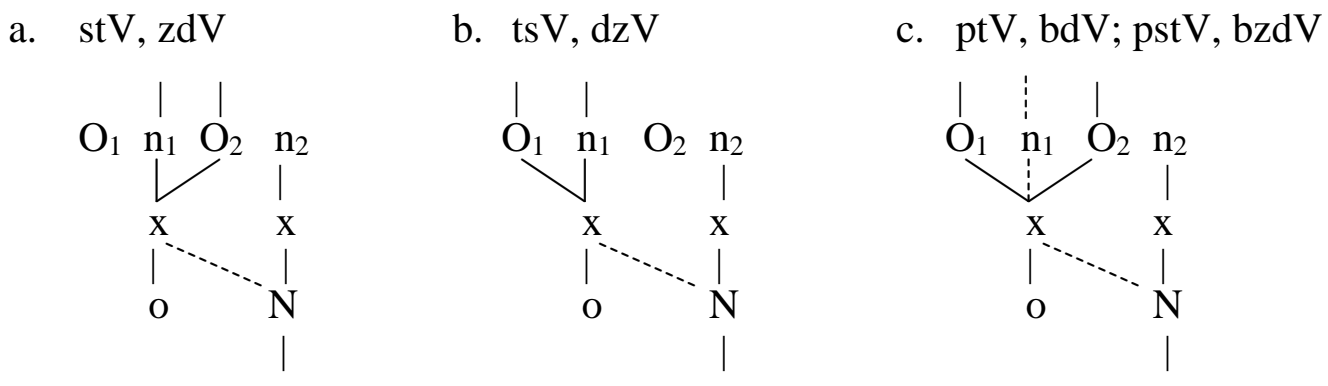

The configuration in (16a) represents the well-known and widespread $\mathrm{sC}$ clusters, as those found in English sky, Latin stare, German Spiegel, etc. Based on two On sequences, (16b)like structures are clusters, like Greek $p s$, $t s, k s$, or Polish $p r z, t r z, k r z$, not affricates. ${ }^{14}$ The heavy clusters in (16c) can be illustrated by Classical Greek plosive+t sequences, as in pterón 'feather', ktêma 'goods'. Georgian "harmonic clusters", in which a labial or a coronal obstruent is followed by a dorsal obstruent (Chitoran 1998), involve either (16b), as in txa 'goat', or (16c), as in bgera 'sound'. Some of the much less constrained obstruent sequences of Polish, as in ptak 'bird', kto 'who', tkać 'weave', bzdura 'nonsense', pstry 'gaudy', may also be assumed to have the configuration in (16c) for reasons that will be discussed below.

Let us mention some theoretical and empirical advantages of the configurations under (16). The first is that Kaye's (1992) Magic Licensing becomes unnecessary in the proposed model: there is no empty nucleus to be licensed in (16a), since $\mathrm{n}_{1}$ is occupied by /s/.

Secondly, the importance of the x-skeleton becomes clear from the representations in (16): it is the skeleton that allows many-to-one associations between the $\mathrm{C}$ - and V-planes; without the skeleton, it would be impossible to link both members of the C-plane nO sequence with both members of the $\mathrm{V}$-plane oN sequence in (16a) without crossing association lines.

Thirdly, the structures in (16) explain why these sequences agree in voicing. Clusters consisting solely of obstruents imply association of several segments to one slot. If voice consists in N propagation onto the preceding onset's slot (cf. Carvalho 2008), all the segments associated with this slot either have voice or lack it, according to whether $\mathrm{N}$ does or not spread.

Furthermore, slot unicity explains why, in Georgian, the syllabic sonorant / $\mathrm{r} /$ can appear optionally only when it is surrounded by consonants with identical laryngeal specifications (Butskhrikidze 2002: 92): cf. prta pta 'wing', grdemli gdemli 'anvil', brdzeni bdzeni 'wise'. If Georgian TRTV sequences undergo a process similar to the one described for French in (14b), the resulting 1-slot clusters under (17b) are highly plausible, as they (i) preserve the laryngeal properties of both obstruents, and (ii) leave no place for $\mathrm{R}$.

\footnotetext{
${ }^{14}$ Affricates will be assumed to involve one melody associated with one single On, whence their homorganicity (cf. Section 5).
} 


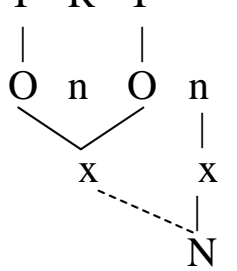

Fourthly, in parallel with the porta / prota alternation discussed above, the configurations in $(16 \mathrm{a}, \mathrm{b})$ explain, through variable $\mathrm{O}-\mathrm{o}$ alignment, the $\mathrm{stV} \leftrightarrow \mathrm{tsV}$ alternation found, e.g., in the Classical Greek pronunciation of the letter $\zeta$, or in non-standard French fi[sk] for fixe 'fixed', Austerli[st] for Austerlitz (Parisian railway station) (cf. Rizzolo and Barillot 2012). ${ }^{15}$

For lack of space, I will not discuss in detail two (possibly related) issues: (i) the licensing mechanism of the empty O's in $(16 \mathrm{a}, \mathrm{b})$; (ii) the fine-grained phonotactic constraints which typically involve place features, and affect the structures under $(13 \mathrm{a}, 16)$. Not only is the first element of $\mathrm{sC}$ clusters typically a coronal, as well as the second member of (13a), but there is also a "labial effect" whereby /f/ often behaves as a plosive, as opposed to the other fricatives, and $/ \mathrm{m} /$ as an obstruent, by contrast with the other nasals. For example, Romance languages generally have /pr, tr, kr/ and /fr/, but not */sr, $\mathrm{xr} /$; English adds $/ \theta \mathrm{r}, \int \mathrm{r} /$ to the list, and Polish allows /xr/ along with $/ \mathrm{mr} /$, but not */nr/. Also, as shown by Greek and Georgian, the second member of the clusters in $(16 b, c)$ is either a coronal or a dorsal, never a labial. ${ }^{16}$ Since labials may be said to be marked vis-à-vis coronals and dorsals (cf. Carvalho 2013, and references therein), this labial effect might well be a strong argument for assuming that segmental complexity (involving place specification) underlies, not sonority proper (cf. Section 2.2), but headedness-based relations in the C-plane between the components of a (16b,c)-like cluster. In that case, such relations might be reversed, as in Cl. Greek (16c) ptV > Mod. (16a) $\mathrm{ftV}$, where it is the labial feature $(p)$ that moves to $\mathrm{n}_{1}$ (giving $/ \mathrm{ft} /$ ), and not the coronal feature $(t)$, which would have given (the existing) /ps/ cluster: if $\mathrm{O}_{1}$ happens to be governed by $\mathrm{O}_{2}$, it is too weak for bearing a labial (cf. Cyran and Gussmann 1999). ${ }^{17}$

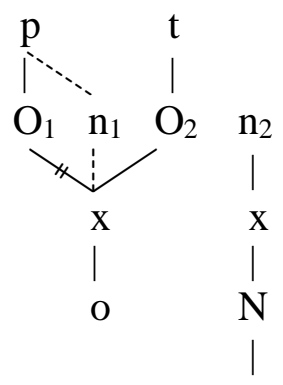

\footnotetext{
${ }^{15}$ It remains to be seen why $/ \mathrm{sC} /$ and $/ \mathrm{Cs} /$ are much less prone to alternating than $/(\mathrm{C}) \mathrm{Vr} /$ and $/(\mathrm{C}) \mathrm{rV} /$.

${ }^{16}$ Though allowing a much larger array of possibilities than Greek, Polish obstruent clusters are not bogus, as they involve laryngeal homogeneity, and do not allow nucleus activation (cf. Section 2.1). Even TRT clusters (as in brdysać 'frolic', drgać 'vibrate', krtań 'larynx', grdyka 'Adam's apple') agree in voice, and are assumed to be asyllabic (cf. Scheer 2009 contra Piotrowski et al. 1992). This is a real problem for the theory proposed here: as $\mathrm{R}$ is based on O-N alignment, TRT involves an enclosed $\mathrm{V}$-plane $\mathrm{N}$; in that case, there is no reason for voice agreement in these clusters. In any case, as a working hypothesis, Polish TT sequences whose second member is a (supposedly unmarked) coronal or dorsal will be viewed as clusters of the types represented under (16b,c). The remaining obstruent clusters will be examined in Section 4.3.

${ }^{17}$ In word-final position, place also plays a crucial role: it is well known that final /s/ and /n, y/ are commonly preferred over $/ \mathrm{f} /$ and $/ \mathrm{m} /$.
} 


\subsection{The skeleton and cluster cohesiveness}

It was assumed in Section 3.2, for the sake of simplicity, that OnOn/oN alignment involves two-slot structures. However, as there are at least three segments in those sequences - a plosive, a sonorant or a fricative, and the vowel -, there might be three slots as well. Indeed, languages do show either 2- or 3-slot configurations, or both. Interestingly, this additional slot entails some remarkable differences. Let us consider three examples.

In the TT sequences under (19a-c), each segment has its own timing slot. It follows that, unlike (16c), such structures allow different laryngeal features, as shown in (19b).

a. $\mathrm{ptV}$

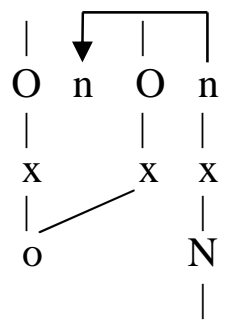

b. $\mathrm{pdV}$

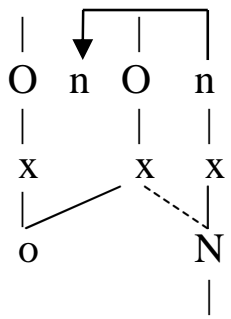

c. bdV

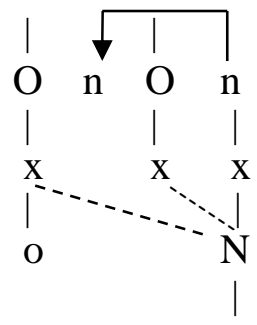

Crucially, if there is only one voiced obstruent in such clusters, it is necessarily the last of the two, owing to locality constraints. This is precisely what we find in Georgian non-harmonic clusters as in tbili 'warm', $t s d a$ 'test', $x d a$ 'pay', $x b o$ 'calf', $t$ 'ba 'lake' (Vogt 1971), ${ }^{18}$ in the so-called "sesquisyllabic" patterns of Khmer (Jacob 1968), and in Yahthe-Fulniô (Wetzels and Mascaró 2001: Ch. 4.3; Meland and Meland 2010). Thus, /bta/-like clusters, if any, are necessarily bogus, voice resulting from the enclosed empty $\mathrm{N}$ in the V-plane. ${ }^{19}$

Apart from this and the absence of nucleus activation, the sequences in (19) are like bogus clusters: possibly because each segment has its own slot in both cases, their combinatorial possibilities are weakly constrained. Such are, for example, many Georgian TT clusters, as well as part of Polish ones (cf. gbur 'boor', dbać 'care').

In Georgian, 3-slot structures shed light on an otherwise mysterious point: $v$-metathesis. ${ }^{20}$ Many languages clearly disallow CCCV syllables with two sonorants between the first consonant and the vowel. In my proposal, these syllables are ruled out because they would imply an OnOnOn sequence in the C-plane with two successive empty nuclei, which violates the ECP. Such clusters are often avoided through diaeresis, that is with a dissyllabic oNoN sequence in the V-plane: compare French [li] (il) lie 'he links' vs [lje] lier 'to link' with [pli] (il) plie 'he folds' $v s$ [plije], and not *[plje], plier 'to fold'. In Georgian, morpheme concatenation might also have led to such illegal forms as $*^{[}\left[\mathrm{k}^{2} \mathrm{rwa}\right]$ or $*\left[\mathrm{k}^{2} \mathrm{lwa}\right]$, but what we

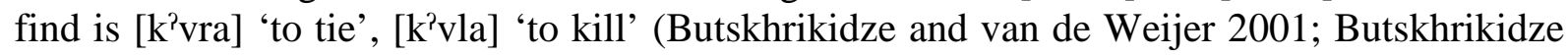
2002: 186-188), with a slightly fricated labial approximant. As shown in (20), Georgian keeps both a single oN sequence in the $\mathrm{V}$-plane, and a short OnOn sequence in the C-plane, which satisfies the ECP but entails $v$-metathesis: since $\mathrm{R}$ supposes $\mathrm{O}-\mathrm{N}$ alignment, there is no other place left for the labial element $(\mathrm{U})$ than the first nucleus of the C-plane.

\footnotetext{
${ }^{18}$ I thus claim, contra Ritter's (2006) analysis, that (most) Georgian non-harmonic TT clusters are not bogus, subject to PG between nuclei; otherwise, voiced+voiceless CC clusters would be allowed.

${ }^{19}$ Interestingly, such clusters are particularly frequent in Georgian TTT sequences (e.g., $b s^{\prime} k^{2} a r i$ 'line'), which necessarily contain a harmonic cluster (Vogt 1971; Butskhrikidze 2002).

${ }^{20}$ I follow here Nepveu's (1994) analysis of Georgian /w/ (generally transliterated as $v$ ) as a defective segment, specified only for a labial place of articulation.
} 
More generally, "sequences of the stop+fricative type are never separated by a sonorant, e.g. sequences such as *brz, *pls, ${ }^{*} g l z$ are not attested" in Georgian (Butskhrikidze 2002: 92): indeed, according to the proposed framework, such sequences suppose three On and two oN sequences, that is one more in both planes than the attested $b z r, p s l$, etc. (cf. Section 4.4).

A last example of 3-slot structure comes from the sequences of the type CV plus fricative coda (resulting from n-o alignment), as in (21), which should be compared with CVR in (13b). I take the opportunity to illustrate the process of compensatory lengthening often associated with such sequences, which is made possible by the additional slot.
a. $[\mathrm{CVsCV}]>\left[\mathrm{CV}^{\mathrm{h}} \mathrm{CV}\right]$ (debuccalization)

b. $\left[\mathrm{CV}^{\mathrm{h}} \mathrm{CV}\right]>[\mathrm{CV}: \mathrm{CV}]$

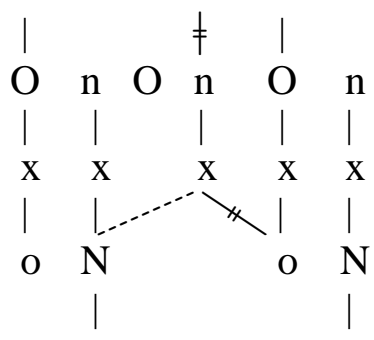

\subsection{Markedness considerations}

The typology of bogus and true clusters suggests that none of the two types can be said to be marked with respect to the other: restricting our analysis to tautomorphemic sequences, and leaving aside marginal items such as certain learned words and loanwords, languages may have only true clusters (Spanish, maybe English), only bogus clusters (Semitic), both (French, Georgian to some extent, maybe Polish) or none (most Bantu languages). It then appears that the constraint which bans empty V-plane N's (in bogus clusters) and the one that prevents the $\mathrm{C}$-plane from being longer than the V-plane (in true clusters) may be differently ranked from language to language.

While bogus clusters may be unbounded, owing to the ECP which applies in the V-plane (cf. Tashlhiyt Berber), the same principle, acting in the C-plane, sets a limit on the size of true clusters. For example, consider the initial TTR sequence of, e.g., Polish tkliwy 'tender' in (22).

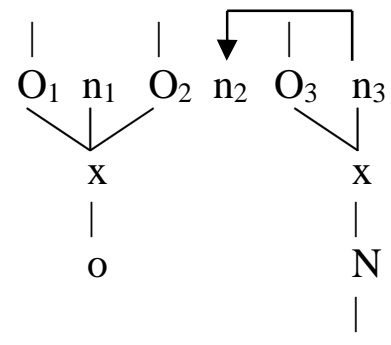

Being governed by $\mathrm{n}_{3}, \mathrm{n}_{2}$ cannot govern $\mathrm{n}_{1}$, which thus anchors to the skeleton. However, only a C-plane $\mathrm{n}$ aligned with a V-plane $\mathrm{N}$ can govern (cf. Section 4.1). Therefore, as it does not 
yield any $\mathrm{n}-\mathrm{N}$ alignment, neither does $\mathrm{n}_{1}$-association generate an additional syllable - it simply formalizes the burst of the first obstruent - nor can $\mathrm{n}_{1}$ govern another $\mathrm{n}$ at its left. As a result, no true cluster containing more than two T's is allowed. Interestingly, the only TTT sequences of Georgian, which incidentally contain a harmonic cluster, necessarily involve a bogus cluster, as its first member may be voiced, as in $b t^{2} k^{2} a r i$ 'line' (cf. Section 4.3).

Furthermore, the proposed theory strongly constrains the shape of true clusters: certain sequences appear as more or less marked than others, and this is built-in into representations (cf. Section 3.1). As shown in (23), initial RT clusters are more marked than \#sT clusters, as they require one additional oN sequence in the V-plane, and one more timing slot.

a. \#RTV-

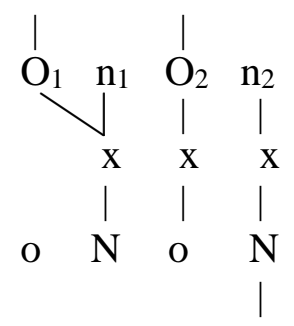

b. \#sTV-

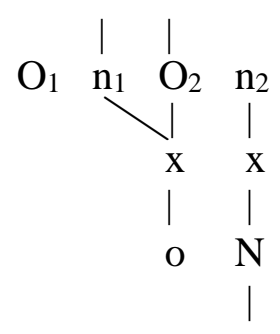

This is indeed the case: I do not know of languages having initial (true) RT clusters without having initial sT clusters as well, although the reverse is commonly attested.

If a language has both (23a) and (23b), \#RTV-is more likely to develop epenthesis than \#sTV-, since, as shown in (24), this simply requires an additional On in the C-plane, but an additional oN in the $\mathrm{V}$-plane, and insertion of one timing slot in \#sTV-.

a. /\#RTV-/ > [\#əRTV-]

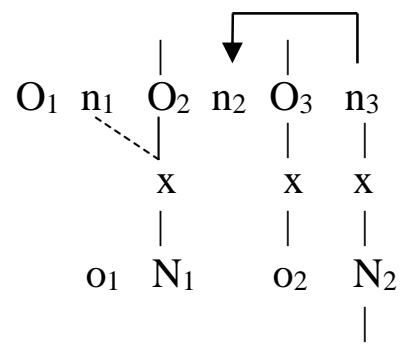

b. /\#sTV-/ > [\#әsTV-]

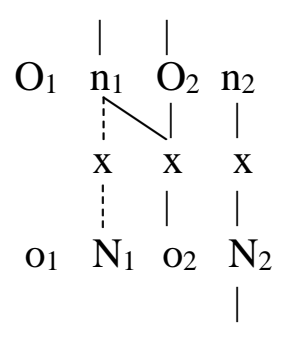

This is attested, for example, in Emilian and Piedmontese dialects of Italo-Romance, in which initial RT clusters triggered epenthesis (Passino 2013), while sT clusters stay unchanged. The reverse - i.e. epenthesis in sT without epenthesis in RT - is assumed to be impossible.

For the same reasons, the opposite is true at the right edge of the word, final sonorants being less marked than final fricatives, as shown in (25).
a. TVR\#
b. TVs\#
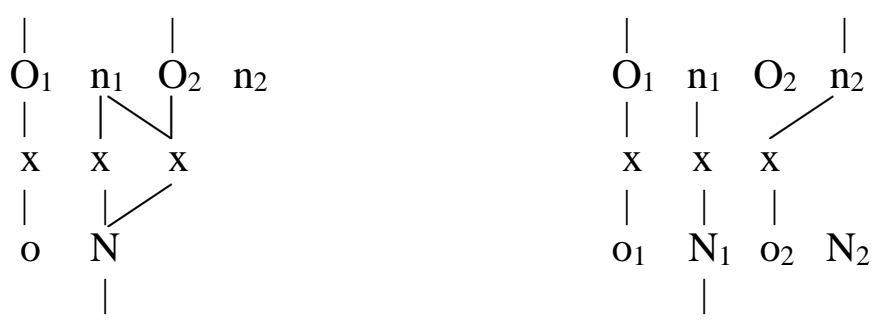
Indeed, not only are there languages that have only sonorant codas word-finally, while none has fricative codas only (cf. Hyman 1985), but whenever both sonorant and fricative codas coexist, either the latter are more likely to fall than the former (as in many Romance languages), or the coda is a bogus one, if any consonant is allowed in that position (cf. Section 2.1). Note also that preconsonantal fricatives, as in (21), are less marked than word-final fricatives, as in (25b): the latter ones require an additional oN, while the former do not.

That being said, markedness issues need further research. As an example of the many problems at stake, consider Ancient Greek which had /s\#/ and /ps\#, ks\#/, but not */p\#, k\#/, that is, respectively, (25b) and (26a), but not (26b).

a. TVTS

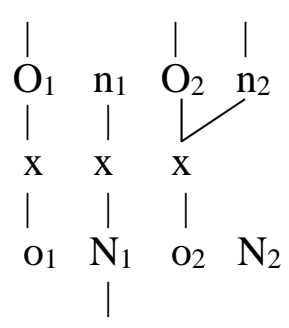

b. TVT

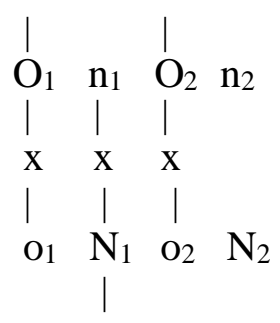

This may seem counterintuitive. The theory described so far may bring the following answer: just as many languages disallow (at least final) codas, that is empty V-plane N's, so did Greek ban word-final empty C-plane n's like the one in (26b).

\section{Outstanding issues and conclusion}

I will now briefly mention three issues that have been left unaddressed. A first question is whether sonority-based categories have specific featural content at all. Indeed, if the C-and $\mathrm{V}$-planes bear consonantal and vocalic melodies respectively, and if plosives, fricatives, sonorants and vowels result from $\mathrm{O}-\mathrm{o}, \mathrm{n}-\mathrm{o}, \mathrm{O}-\mathrm{N}$ and $\mathrm{n}-\mathrm{N}$ alignments between the $\mathrm{C}-$ and $\mathrm{V}-$ planes, are such features as [ \pm consonantal], [ \pm sonorant $]$ and [ \pm continuant $]$ still relevant? If not, how should fricatives and sonorants be represented outside clusters, that is in isolation? The representations under $(27 \mathrm{a}, \mathrm{b})$ follow from previous discussion.

(27) $\mathrm{a}$

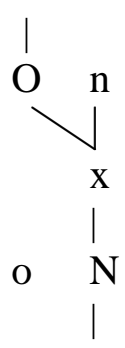

b.

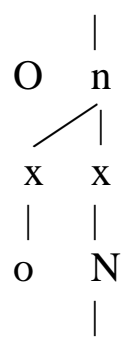

c.

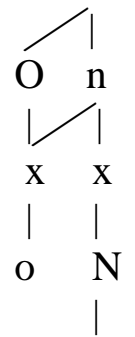

(27a), with the consonant associated with an O-N alignment, stands for /RV/. Note that the fact that the onset lacks any slot of its own onto which $\mathrm{N}$ could propagate rules out voice contrasts among sonorants. (27b), with the consonant associated with a n-o alignment, is supposed to underlie fricatives, which only differ from (homorganic) affricates in that the latter also involve, as shown in (27c), O-o alignment, that is plosiveness.

Another point is the question of metrical weight. Whether a consonant is or not "moraic" depends on whether a weight unit - say, a mora - is or not associated with the nucleus. It seems that metrical visibility of nuclei is independent from whether they belong to a bogus or 
to a true cluster: Somali codas are metrically null, while implying an empty $\mathrm{N}$ in the V-plane; on the other hand, Romance sonorant codas have weight, though involving an empty $n$ in the C-plane only. Thus, weight may or may not be sensitive to both planes, since both V-plane $\mathrm{N}$ 's and C-plane n's may or may not contain a mora. Only V-plane N's, however, can generally be stress-bearing units.

A last point should be addressed here. My whole proposal on clusters and consonant phonotactics is based on the assumption that the $\mathrm{ON}$ sequences located on the $\mathrm{C}$ - and the $\mathrm{V}$ planes may have different lengths, and that (true) consonant clusters emerge when the sequence on the $\mathrm{C}$-plane is longer than the one on the V-plane. But what about the reverse configuration, in which the sequence on the V-plane would be longer than the one on the Cplane? Clearly, if one of the two cases is assumed to exist, the same goes for the other. I propose that, symmetrically, such configurations give place to "true vowel clusters", that is either diphthongs or vowel-glide sequences, as opposed to hiatuses, which are "bogus vowel clusters", involving, just like their consonantal counterparts, C- and V-planes of equal length.

By way of concluding, whatever outstanding issues may remain, the proposed account of consonant clusters and related constraints is interesting for at least four reasons. First, and most importantly, the major phonotactic restrictions, based on sonority, become motivated, as they directly follow from representations, and no longer from stipulations on representations.

Secondly, this is achieved by means that are familiar to phonologists since the advent of autosegmental formalism. As is the case with length or the tonal patterns of African languages, the point resides in how objects of different sizes are synchronized, and in which alignment types are favoured.

Thirdly, as was seen in Section 4, the multiplanar representations shed interesting light on several empirical issues. Besides a clear distinction between bogus and true clusters, they offer a rich typology of the latter ones, based on the alignment types and on the number of skeletal slots involved. Also, the proposed structures naturally account for several processes such as liquid metathesis and deletion, vowel epenthesis, plosive fricativization, and compensatory lengthening, while providing us with a means for measuring the relative likelihood of some of them on the basis of representational markedness.

Finally, the proposed framework supports the Strict CV model in that it retains its basic idea - "CV as the only syllable type" - while removing a major barrier encountered by the theory as it stands - arbitrariness. Just as in standard Strict CV, there are no such things as rhymes or branching onsets in my proposal; nor is there, though, any need for principle ranking, or ad hoc statements on the "licensing potential" of certain positions insofar as sonority is concerned.

\section{References}

Blaho, Sylvia. 2008. The syntax of phonology. A radically substance-free approach. University of Troms $\varnothing$ doctoral thesis.

Butskhrikidze, Marika. 2002. The Consonant Phonotactics of Georgian. Utrecht: LOT.

Butskhrikidze, Marika. \& Jeroen Maarten van de Weijer. 2001. On v-metathesis in Modern Georgian. In Elizabeth V. Hume, Norval Smith \& Jeroen Maarten van de Weijer (eds.), Surface syllable structure and segment sequencing (HIL Occasional Papers 4), 91-101. Leiden: Holland Institute of Generative Linguistics.

Carvalho, Joaquim Brandão de. 2008. From positions to transitions: A contour-based account of lenition and fortition. In Joaquim Brandão de Carvalho, Tobias Scheer \& Philippe Ségéral (eds.), Lenition and fortition, 415-445. Berlin: Mouton de Gruyter. 
Carvalho, Joaquim Brandão de. 2013. Why there is no backness: the case for dismissing both [coronal] and [dorsal]. In Jean Léo Léonard \& Samia Naïm (eds.), Backness and backing, 45-58. Munich: Lincom.

Charette, Monik. 1991. Conditions on phonological government. Cambridge: Cambridge University Press.

Chitoran, Ioana. 1998. Georgian harmonic clusters: phonetic cues to phonological representation. Phonology 15. 121-141.

Chomsky, Noam \& Morris Halle. 1968. The sound pattern of English. New York: Harper \& Row.

Clements, George N. 1990. The role of the sonority cycle in core syllabification. In John Kingston \& Mary E. Beckman (eds.), Between the grammar and the physics of speech (Papers in Laboratory Phonology 1), 283-333. Cambridge: Cambridge University Press.

Clements, George N. \& Samuel Jay Keyser. 1983. CV Phonology: A generative theory of the syllable. Cambridge, Mass.: The MIT Press.

Cyran, Eugeniusz. 2008. Consonant clusters in strong and weak positions. In Joaquim Brandão de Carvalho, Tobias Scheer \& Philippe Ségéral (eds.), Lenition and fortition, 447-481. Berlin: Mouton de Gruyter.

Cyran, Eugeniusz. 2010. Complexity scales and licensing in phonology. Berlin: Mouton de Gruyter.

Cyran, Eugeniusz \& Edmund Gussmann. 1999. Consonantal clusters and governing relations: Polish initial consonant sequences. In Harry van der Hulst \& Nancy A. Ritter (eds.), The Syllable. Views and Facts, 219-247. Berlin: Mouton de Gruyter.

Encrevé, Pierre. 1988. La liaison avec et sans enchaînement. Phonologie tridimensionnelle et usages du français. Paris: Seuil.

Fujimura, Osamu. 1992. Phonology and phonetics: A syllable-based model of articulatory organization. Journal of the Acoustical Society of Japan 13.E. 39-48.

Goldsmith, John. 1990. Autosegmental and metrical phonology. Oxford: Blackwell.

Gussmann, Edmund \& Jonathan Kaye. 1993. Polish notes from a Dubrovnik cafe. I. The yers'. SOAS Working Papers in Linguistics and Phonetics 3. 427-462.

Harris, John. 1990. Segmental complexity and phonological government. Phonology 7. 255-300.

Harris, John. 1997. Licensing Inheritance: an integrated theory of neutralization. Phonology 14. 315370.

Hyman, Larry M. 1985. A theory of phonological weight. Dordrecht: Foris.

Jacob, Judith M. 1968. Introduction to Cambodian. Oxford: Oxford University Press.

Jespersen, Otto. 1913. Lehrbuch der Phonetik. Leipzig-Berlin: Teubner.

Kaye, Jonathan. 1992. Do you believe in magic? The story of S+C sequences. SOAS Working Papers in Linguistics and Phonetics 2. 293-313.

Kaye, Jonathan, Jean Lowenstamm \& Jean-Roger Vergnaud. 1990. Constituent structure and government in phonology. Phonology 7. 193-231.

Kuryłowicz, Jerzy. 1948. Contribution à la théorie de la syllabe. Biuletyn Polskiego Towarzystwa Językoznawczego 8. 80-104.

Kuryłowicz, Jerzy. 1952. Uwagi o polskich grupach spółgłoskowych. Biuletyn Polskiego Towarzystwa Językoznawczego 11. 54-69.

Lai, Rosangela. 2013. Positional effects in Sardinian muta cum liquida. Lenition, metathesis, and liquid deletion. Alessandria: Ed. dell'Orso.

Léon, Pierre R. 1996 [1992]. Phonétisme et prononciations du français, $2^{\text {nd }}$ edn. Paris: Nathan.

Lowenstamm, Jean. 1996. CV as the only syllable type. In Jacques Durand \& Bernard Laks (eds.), Current trends in phonology: models and methods, vol. 2, 419-441. CNRS, Paris X: ESRI.

Macken, Marlys A. 1992. Where's phonology? In Charles A. Ferguson, Lise Menn \& Carol StoelGammon (eds.), Phonological development: Models, research, implications, 249-269. Timonium, Maryland: York Press. 
Martins, Maria Raquel Delgado. 1986. Sept études sur la perception. Lisbon: Instituto Nacional de Investigação Científica.

McDonough, Joyce \& Scott Myers. 1991. Consonant harmony and planar segregation in child language. UCLA and University of Texas, Austin, ms.

Meland, Douglas \& Doris Meland. 2010. Phonemic Statement of the Fulniô Language. Anápolis: Associação Internacional de Linguística - SIL Brasil.

Nepveu, Denis. 1994. Georgian and Bella Coola: Headless syllables and syllabic obstruents. University of California Santa Cruz MA thesis.

Obleser, Jonas, Amber M. Leaver, John VanMeter \& Josef P. Rauschecker. 2010. Segregation of vowels and consonants in human auditory cortex: evidence for distributed hierarchical organization. Fronplanes in Psychology 1, article 232.

Öhman, Sven E. G. 1966. Coarticulation in VCV utterances: Spectrographic measurements. Journal of the Acoustical Society of America 39. 151-68.

Passino, Diana. 2013. The phonotactics of word-initial clusters in Romance: typological and theoretical implications. In Sergio Baauw, Frank Drijkoningen, Luisa Meroni \& Manuela Pinto (eds.), Romance languages and linguistic theory 5, 175-191. Amsterdam: Benjamins.

Pike, Kenneth \& Eunice Pike. 1947. Immediate constituents of Mazateco syllables. International Journal of American Linguistics 13. 78-91.

Piotrowski, Marek, Iggy Roca \& Andrew Spencer. 1992. Polish yers and lexical syllabicity. The Linguistic Review 9. 27-67.

Rice, Keren. 1992. On deriving sonority: a structural account of sonority relationships. Phonology 9. 61-99.

Ritter, Nancy A. 2006. Georgian Consonant Cluster: The complexity is in the structure, not the melody. The Linguistic Review 23. 429-464.

Rizzolo, Olivier \& Xavier Barillot. 2012. Où s'accroche le [s] dans les groupes sC en français? Paper presented at the $10^{\text {th }}$ meeting of the Réseau Français de Phonologie, Paris, 25-27 June.

Scheer, Tobias. 2004. A lateral theory of phonology: What is CVCV, and why should it be? Berlin: Mouton de Gruyter.

Scheer, Tobias. 2009. Syllabic and trapped consonants in the light of branching onsets and licensing scales. In Gerhild Zybatow, Uwe Junghanns, Denisa Lenertová \& Petr Biskup (eds.), Studies in formal Slavic phonology, morphology, syntax, semantics and information structure, 411-426. Frankfurt: Peter Lang.

Scheer, Tobias \& Péter Szigetvári. 2005. Unified representations for the syllable and stress. Phonology 22. 37-75.

Selkirk, Elisabeth. 1984. On the major class features and syllable theory. In Mark Aronoff \& Richard T. Oehrle (eds.), Language sound structure: Studies in phonology presented to Morris Halle by his teacher and students, 107-136. Cambridge: MIT Press.

Szigetvári, Péter. 1999. VC phonology: A theory of consonant lenition and phonotactics. Budapest: Eötvös Loránd University-Hungarian Academy of Sciences dissertation.

Vogt, Hans. 1971. Grammaire de la langue géorgienne. Oslo: Universitetsvorlaget.

Wetzels, Willem Leo \& Joan Mascaró. 2001. The typology of voicing and devoicing. Language 77. 207-44.

Zec, Draga. 2007. The syllable. In Paul de Lacy (ed.), The Cambridge handbook of phonology, 161194. Cambridge: Cambridge University Press. 